\title{
Quantitative morphology and water distribution of bronchial biopsy samples
}

\author{
D R Baldwin, R Wise, J M Andrews, D Honeybourne
}

\begin{abstract}
Background An approach to the study of the pharmacokinetics of drugs in the lung is to measure their concentrations in bronchial biopsy specimens. The main criticism of this technique is that bronchial biopsy specimens consist of more than one tissue type and that drugs are often not distributed evenly. The morphology of bronchial biopsy specimens and the distribution of water between the extracellular and the intracellular compartments is therefore important.

Methods Fifteen subjects undergoing fibreoptic bronchoscopy each had four bronchial biopsy samples taken. Thirty sections from 10 patients were examined and the proportion of tissue types noted, a morphometric analysis computer being used. The water distribution was investigated in the other biopsy specimens with radiolabelled markers.

Results There was pronounced variation in the relative proportions of tissue types. Ciliated epithelium occupied a mean of $22 \cdot 3 \%$ of the biopsy sample, submucosa $53.4 \%$, muscle $17.6 \%$, and glandular tissue $\mathbf{7 \cdot 0 \%}$. There were no differences between second and the fourth generation subcarinae and macroscopic normality of the mucosa was a good predictor of histological normality. The extracellular water content was $40 \%$ of the total weight of the specimen and the total water content was $70 \%$.
\end{abstract}

Conclusions These data provide the basis for pharmacokinetic study of drugs in bronchial mucosa. They show for pharmacokinetic study that macroscopically normal mucosa may be assumed to be histologically normal; that multiple biopsy specimens should be taken for any study, as there is considerable variation in the proportion of tissue types; that specimens from second and fourth generation subcarinae are the same; and that extracellular water contributes $40 \%$ to the total weight of the biopsy specimen.

Thoracic Medicine

D R Baldwin

$\mathrm{R}$ Wise

Department of Medical Microbiology

J M Andrews

D Honeybourne

Dudley Road Hospital,

Birmingham B18 7QH

Reprint requests to:

Dr D R Baldwin
A recent approach to the pharmacokinetic assessment of drugs has been to measure the concentrations reached in lung tissues. Biopsy specimens of the bronchial mucosa are used to assess the pharmacokinetics of antimicrobials in bronchial mucosa to predict efficacy in bronchial mucosal infection..$^{1-3} \mathrm{~A}$ criticism of the measurement of concentrations of drugs in bronchial biopsy specimens is that the tissue consists of several different types and consequently the distribution of the drug may be uneven. ${ }^{4}$ Thus to interpret concentrations in biopsy specimens it is important to know the relative contributions of each tissue type. The term macroscopically normal has been used in several publications, and has been defined as a "bronchial mucosa that appears bronchoscopically to be free from erythema, oedema, nodularity or friability." 67 The relationship of this definition to histological normality requires further investigation, and the variation of the morphology in relation to site from which the biopsy is taken requires evaluation.

A major factor affecting drug distribution is the proportion of cellular and extracellular tissue because drugs are partitioned by the cell membrane. The water distribution within bronchial biopsy specimens can be used to estimate the size of the intracellular and extracellular compartments and is important for interpreting drug concentrations.

The aims of the study were therefore to determine the morphology of bronchial biopsy specimens and their quantity of extracellular water as a proportion of total water.

\section{Methods}

SUBJECTS

We studied 15 patients who were undergoing fibreoptic bronchoscopy for diagnostic purposes. The final diagnosis was lung cancer in four, chronic airflow obstruction in six, suspicious hilar shadowing in three, and haemoptysis only in two. This range of diagnoses is similar to that found in patients enrolled in pharmacokinetic studies of antimicrobials. ${ }^{3-7}$ They gave informed consent for additional bronchial biopsy specimens to be taken and the study was approved by the hospital ethical committee. Patients were not selected for study if they had any evidence of pulmonary infection.

\section{BRONCHIAL BIOPSY SPECIMENS}

Bronchoscopy was performed with a premedication of $0.6 \mathrm{mg}$ intramuscular atropine and $160 \mathrm{mg}$ nebulised $4 \%$ lignocaine, and $3-5 \mathrm{mg}$ of intravenous midazolam as a sedative. After careful inspection of the airways and before any diagnostic procedure four bronchial biopsy specimens were taken from 
each patient from macroscopically normal subcarinal mucosa with non-crushing forceps. The site of each biopsy was noted. Specimens to be used for histological study were orientated with the mucosa uppermost on a fine gauze square, and those intended for study of water content were placed in culture media (RPMI 1640 media (Flow Laboratories, High Wickham) and $10 \%$ fetal calf serum) at $37^{\circ} \mathrm{C}$ and transported to the laboratory immediately.

\section{HISTOLOGICAL STUDY}

The histological investigation included the assessment of biopsy specimens from different sites, morphometric measurements of the relative amounts of the components of each tissue type, and noting the presence of inflammatory infiltrates. The orientated biopsy specimens from 10 patients were fixed in formalin, stained with haematoxylin and eosin, and mounted in wax. Three slices, going from the mucosal surface to the deep surface, were taken from each specimen. The slides were examined microscopically as follows:

1 The presence of acute or chronic inflammatory cell infiltration was noted (neutrophils, lymphoid infiltration, or epithelioid cells).

2 The relative quantities of tissue types were estimated by calculating the proportion of the area occupied by each type. This was facilitated by the use of a computer program designed for morphometric analysis of tissues. Each slide was projected on to a plate overlying a digitising grid (Kontron Computers, Image Analysis Division). The image of each tissue type was then encircled with a pressure sensitive pen, which enabled the computer to calculate the area of the slide occupied by the various tissue types. The types defined were ciliated respiratory epithelium, submucosal stroma, muscle and glandular tissue. Other components (such as blood vessels) occupied a very small area and were not included.

3 Biopsy specimens from fourth generation subcarinae were compared with those from the main carina and the second generation for differences in the proportions of tissue types.

\section{MEASUREMENT OF INTRACELLULAR AND}

EXTRACELLULAR WATER CONTENT OF BRONCHIAL BIOPSY SPECIMENS

Bronchial biopsy specimens were taken fresh from the bronchoscopy suite, in culture medium (RPMI $1640+10 \%$ fetal calf serum) at $37^{\circ} \mathrm{C}$, and incubated with either tritiated water $\left({ }^{3} \mathrm{H}_{2} \mathrm{O}\right),{ }^{14} \mathrm{C}$ inulin, or ${ }^{14} \mathrm{C}$ polyethylene

Table 1 Proportions of tissue types in bronchial biopsy specimens

\begin{tabular}{|c|c|c|c|c|}
\hline & \multicolumn{4}{|c|}{ Proportions of each tissue (\%) } \\
\hline & Epithelium & Submucosa & Muscle & Glands \\
\hline \multicolumn{5}{|l|}{ All biopsies } \\
\hline $\begin{array}{l}\text { Mean } \\
\mathbf{9 5 \%} \text { confidence limits }\end{array}$ & $\begin{array}{l}22 \cdot 3 \\
20 \cdot 2 \text { to } 24 \cdot 5\end{array}$ & $\begin{array}{l}53 \cdot 4 \\
50 \cdot 8 \text { to } 56 \cdot 8\end{array}$ & $\begin{array}{l}17.6 \\
12.9 \text { to } 22.4\end{array}$ & $\begin{array}{l}7 \cdot 0 \\
4 \cdot 2 \text { to } 9 \cdot 8\end{array}$ \\
\hline \multicolumn{5}{|l|}{ Subcarinae } \\
\hline Second generation mean & $23 \cdot 3$ & $53 \cdot 7$ & $15 \cdot 2$ & $7 \cdot 8$ \\
\hline Fourth generation mean & $21 \cdot 4$ & $53 \cdot 1$ & $20 \cdot 1$ & $6 \cdot 3$ \\
\hline $\begin{array}{l}\text { Difference between means } \\
95 \% \text { confidence of difference }\end{array}$ & $\begin{array}{l}1.9 \\
-2.5 \text { to } 6.31\end{array}$ & $\begin{array}{l}0.6 \\
-6.3 \text { to } 7.5\end{array}$ & $\begin{array}{l}5 \cdot 1 \\
-4 \cdot 3 \text { to } 14 \cdot 6\end{array}$ & $\begin{array}{l}1 \cdot 4 \\
-4 \cdot 3 \text { to } 7 \cdot 1\end{array}$ \\
\hline
\end{tabular}

glycol for 20 minutes. The tritiated water was a marker of the total water content of the biopsy specimen as water permeates tissues rapidly and equilibrates with all tissue compartments. ${ }^{8}$ The biopsy specimens were then gently blotted with filter paper to remove surface fluid, weighed, homogenised by ultrasonication after the addition of $200 \mu \mathrm{l}$ water, and then added to $10 \mathrm{ml}$ aqueous counting scintillant (NE 260, Nuclear Enterprises, Edinburgh) and counted for four minutes (Canberra Packard Tricare, Pangbourne, Berkshire). The total water and extracellular water content was then calculated as follows:

Tritiated water sample:

Total volume of water $(\mu \mathrm{l})=$ count of sample count of $1 \mu \mathrm{l}$ of culture medium

Inulin and ${ }^{14} \mathrm{C}$ polyethylene glycol samples:

Extracellular water volume $(\mu \mathrm{l})=$ count of sample

count of $1 \mu \mathrm{l}$ of culture medium

These volumes are divided by the weight of the biopsy specimens to obtain the fraction of the specimen occupied by the water compartments.

\section{STATISTICAL METHODS}

The proportions of tissue types in biopsy specimens taken from different subcarinae and the extracellular water content of the specimens in which measurements were based on the two different markers were compared by means of Student's $t$ test.

\section{Results}

HISTOLOGICAL STUDY

In all, 30 sections, from 10 patients, were examined. There was evidence of a mild inflammatory cell infiltrate in two sections. This consisted of increased numbers of neutrophils in the submucosa. The third section from this patient did not show features of acute inflammation. Two patients showed clear evidence of goblet cell hyperplasia of the mucosa. In no specimen was there severe distortion of the bronchial morphology, which might be considered to be a cause of variability of drug distribution.

There was considerable variability in the proportions of tissue types. In some biopsy specimens there was no glandular tissue or muscle, and in two there was as much as $22 \%$ and $47 \%$. Table 1 shows the mean proportions of the area of the sample occupied by each tissue type, with the $95 \%$ confidence intervals. The mean proportions of tissue types obtained from different subcarinae are also shown in table 1 , with the difference between means and the $95 \%$ confidence interval for the difference. No significant difference between second and fourth generation subcarinae was shown, though the considerable variability of the biopsy specimens means that any difference would have to be large to reach statistical significance. The mean proportions of the area occupied by the tissue types were $53.4 \%$ submucosal stroma, $22 \cdot 3 \%$ ciliated respiratory 
Table 2 Water content and distribution in bronchial biopsy specimens

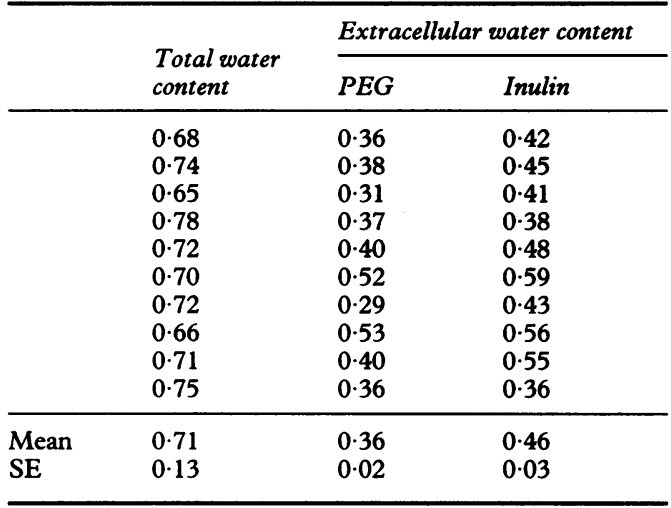

«The fraction of the specimen occupied by total water and extracellular water is given for all experiments, including two methods for measuring extracellular water. PEG-polyethylene glycol.

epithelium, $17 \cdot 6 \%$ muscle, and $7 \cdot 0 \%$ glandular tissue.

\section{MEASUREMENT OF WATER CONTENT OF}

BRONCHIAL BIOPSY SPECIMENS

The total and extracellular water content was calculated for 30 bronchial biopsy specimens, 10 being used for each marker. Table 2 shows the values obtained. The values obtained with inulin as a marker were significantly higher than when polyethylene glycol was used. This probably reflects the small amount of inulin absorbed by cells. ${ }^{9}$ From these data we can assume that the extracellular water content of bronchial mucosal biopsy specimens is about $40 \%$, with considerable variation $(29-59 \%)$.

\section{Discussion}

This study has provided information about the water content and morphological nature of bronchial biopsy samples, which enables us to interpret the concentrations of drugs found at this heterogeneous site. The histological study showed that only a fifth of the sample was mucosal tissue (ciliated respiratory epithelium) and that over half of the constituent tissue was submucosa, composed of largely acellular material. Thus use of the term bronchial mucosal concentrations to describe drug concentrations in biopsy specimens from bronchial mucosa is misleading. ${ }^{1-3}$ Another important observation was the variable quantities of different tissues within the samples This might be one cause of the variation noted in concentrations of $\beta$ lactam antimicrobials in individual bronchial biopsy specimens ${ }^{1-36}$ as antimicrobials are known to be distributed unevenly in tissues. This source of variability will be reduced by the fact that most assayed samples are pooled from four to six separate biopsy specimens from each patient.

No differences in composition were found between biopsy specimens taken from second generation subcarinae and those from the fourth generation, so that for pharmacokinetic studies the site of biopsy is unlikely to be an important source of error. The histological study also showed that there was little inflammation present in samples from areas of macroscopically normal mucosa. The presence of unsuspected inflammation is therefore an unlikely cause of variability of drug concentrations. Some specimens showed goblet cell hyperplasia, which may influence pharmacokinetics, though this requires further study.

Although other data exist on the histological composition of bronchial mucosal biopsy specimens, there is little information that quantifies the distribution of water within specimens-particularly the contribution of extracellular and total water to the weight of biopsy specimens. This is perhaps more important than histological studies because the major source of variation of drug concentrations within a tissue is the relative sizes of the intracellular and extracellular spaces. Using markers of the extracellular environment, we found a variable percentage of extracellular fluid $-29-59 \%$ of the total weight of tissue. The values obtained when inulin was used as a marker were higher than those obtained with polyethylene glycol. This is consistent with the finding that inulin may permeate the cell membrane to some degree. 9

The usefulness of knowing the distribution of water in bronchial biopsy specimens may be illustrated by using antimicrobials as an example. The total water content of samples was about $70 \%$. This is important because the concentration of antimicrobials in bronchial biopsy specimens is expressed in $\mathrm{mg} / \mathrm{kg}$, denoting the total tissue concentration. Thus to obtain a weight of antibiotic per volume of tissue water it is necessary to divide by 0.7 . The water content of serum, where about $8 \%$ of the total volume consists of protein, is about $92 \%$ and of a cell $80 \% .{ }^{10}$ Most antimicrobials pass freely from capillaries into the interstitium and extracellular fluid and therefore interstitial fluid concentrations can be assumed to be equivalent to serum concentrations. ${ }^{11}$ An indirect method for estimating the precise concentration of drugs in the intracellular fluid can be based on the data derived from this study. The mean biopsy sample to serum ratio for the 4-quinolone antimicrobial ciprofloxacin is $1 \cdot 8 .^{3}$ On the assumption of a serum concentration of $1 \mathrm{mg} / \mathrm{l}$, the antimicrobial distribution can be calculated as follows:

Serum concentration

$$
=1.0 \mathrm{mg} / \mathrm{l}
$$

Extracellular fluid concentration

$(\approx$ interstitial fluid concentration $)=1.0 \mathrm{mg} / 1$

Percentage of extracellular water $\quad=40 \%$

Therefore cellular concentration $=1.0 \times(1.8-0.4)$

This series of experiments has answered the question "What is a bronchial mucosal biopsy specimen?" from the point of view of the measurement of drug concentrations in such tissue. Further work could attempt to measure the concentrations of drugs such as antimicrobials reached in individual components of the bronchial biopsy specimen, such as submucosa, ciliated epithelium, and the mucus layer, in order to define the distribution more precisely. 
1 Marlin GE, Braude PD, Whelan AJ, Somogyi AA. Penetration of enoxacin in human bronchial mucosa. Am Rev Respir Dis 1986;134:1209-12.

2 Marlin GE, Burgess KR, Burgoyne J, Funnell GR, Guiness MDG. Penetration of piperacillin into bronchial mucosa and sputum. Thorax 1981;36:774-780.

3 Honeybourne D, Andrews JM, Ashby JP, Lodwick R, Wise $R$. Evaluation of the penetration of ciprofloxacin and amoxycillin into the bronchial mucosa. Thorax 1988; 43:715-9.

4 Schentag JJ. Clinical significance of antibiotic tissue penetration. Clin Pharmacokinet 1989;16 (suppl 1):25-31.

5 Marlin GE, Nicholls AJ, Funnell GM, Bradbury $R$. Penetration of cefaclor into bronchial mucosa. Thorax 1984;39:813-7.

6 Baldwin DR, Wise R, Andrews JM, Ashby JP, Honeybourne D. Cefpirome penetration into the potential sites of pulmonary infection. $J$ Antimicrob Chemother 1991;28:79-86.

7 Baldwin DR, Wise R, Andrews JM, Ashby JP, Honeybourne D. Azithromycin concentrations at the sites of pulmonary infection. Eur Respir J 1990;3:886-90.

8 Paganelli CV, Solomon AK. The rate of exchange of tritiated water across the human red cell membrane. J Gen Physiol 1974;41:259.

9 Chow S, Jee W, Taylor GN, Woodbury DM. Radioautographic studies of inulin sulfate and chloride in rat and guinea pig thyroid glands. Endocrinology 1965;77:818-24.

10 Giese AC. Cell physiology. 5th ed. London: Saunders, 1979:85-6.

11 Barza M, Cuchural G. General principles of antibiotic tissue penetration. Antimicrob Agents Chemother 1985;15 (suppl A):59-75. 